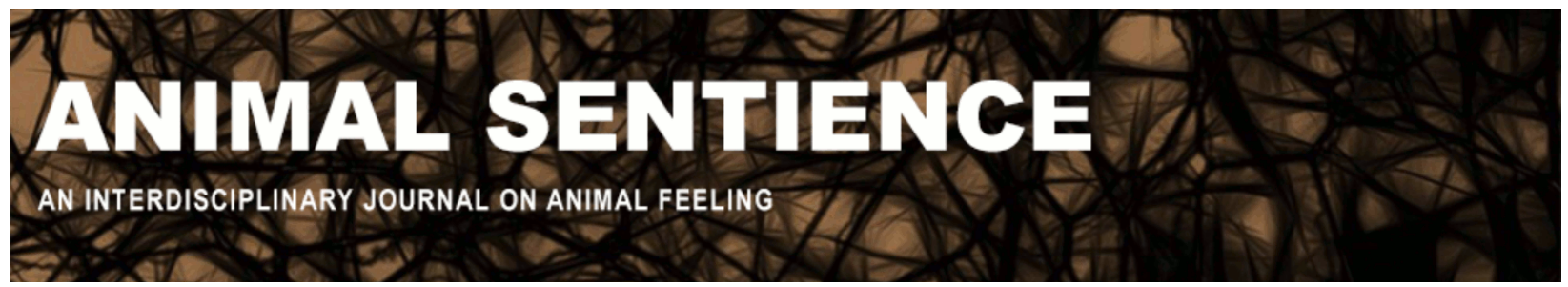

Sevillano, Veronica (2019) Our ambivalent stereotypes of sheep. Animal Sentience 25(35)

DOI: $10.51291 / 2377-7478.1462$

Date of submission: 2019-05-27

Date of acceptance: 2019-06-10 (c) 


\title{
Our ambivalent stereotypes of sheep
}

Commentary on Marino \& Merskin on Sheep Complexity

\author{
Verónica Sevillano \\ Department of Social Psychology and Methodology \\ Autónoma University of Madrid, Spain
}

\begin{abstract}
Marino \& Merskin's target article contrasts our ambivalent social ideas about sheep with the empirical evidence of their complex capacities, particularly cognitive ones. To extend our understanding of human-sheep relations, I discuss human social perception of animals and structural variables that predict our stereotypes.
\end{abstract}

\begin{abstract}
Verónica Sevillano, Assistant Professor of Social and Environmental Psychology at Autónoma University of Madrid, Spain studies empathy and cognitive biases in environmental concern, social stereotypes of animals, and human-animal relations. Website
\end{abstract}

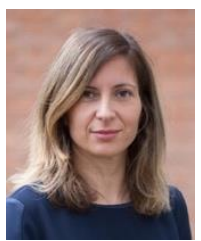

Human social perception of animals. Marino \& Merskin (2019) (M\&M) suggest that popular songs, natural history books and linguistic studies (metaphors) promote the social image of sheep as unintelligent and dependent, but they do not take into account recent work on the psychology of the relations between human and nonhuman animals (Amiot \& Bastian, 2015). Research on "mind perception" and stereotypes is relevant to how people perceive animals (including their physical appearance, as noted by Franklin, 2019). Mind perception researchers study how people make sense of the mental life of others. Gray, Gray \& Wegner (2007) argue in favour of two main components in mental life: agency (e.g., planning) and experience (e.g., hunger). Wiesman, Dweck \& Markman (2017) propose three components: physiological sensations, emotions and perceptual-cognitive capacities. M\&M provide evidence for the existence of these capacities in sheep. The distinct components of their mental life can have implications for moral reasoning about animals.

Research on stereotype content has highlighted the importance of two variables in how people perceive people as well as animals: warmth (intent) and competence (capacity) (Fiske, Cuddy, Glick \& Xu, 2002). In human/animal interactions, it is important for humans to discern whether the animals are dangerously or sociably inclined as well as how capable they are of acting on their inclinations (e.g., intelligence and strength). These two factors are relevant to the stereotypes humans form of animals. M\&M, focused on the cognitive capacities of sheep, do not analyze how people perceive sheep intentions and abilities. What are the sheep's abilities as seen by lay people? Grazing, providing wool and milk? What are the sheep's intentions towards humans? Since sheep's abilities and intentions may not be clearly perceived as important or relevant for humans, their stereotype will remain negative even if they are cognitively complex and sophisticated. 
According to our model of stereotype content applied to animals (Sevillano \& Fiske, 2016) also mentioned by Franklin), sheep are arguably similar to cows, who are perceived as moderately friendly and unintelligent animals. M\&M challenge the assumption that sheep lack intelligence (competence), but the moderately friendly intent (warmth) of sheep toward humans seems unproblematic. Our research, however, found that indifference, a negative emotion, was the main emotion associated with sheep (low competence, moderate warmth). It is their lack of hostile intent, understood as tameness or passivity rather than friendliness toward humans, together with their low competence, that makes sheep targets of exploitation.

Examples of the negative correlates of social stereotypes can be identified throughout M\&M's target article. Stereotypes can bias the social perception of sheep. Research is biased toward production issues and a view of sheep as uniform. Stereotypes and their accompanying labels can legitimize mistreatment. Sevillano \& Fiske (in press) show that animals hurt in an accident are more likely to be ignored if they are perceived as incompetent (e.g., sheep) than if they are perceived as competent (e.g., lions, dogs).

Structural variables predict stereotype content. Two structural variables may influence the content of stereotypes (Fiske et al., 2002): The status of human social groups in society (high or low) influences their perceived competence. Human competitiveness (or lack of cooperation) reduces perceived warmth. In the case of animals, their status and degree of conflict with humans (cooperation differences) depend on social context (e.g., food industry, therapeutic settings, protected areas, household settings, entertainment). This too can make the evidence of sheep cognitive capacities less consequential. As sheep are inserted in a social structure that considers them animals for the production of goods, they are considered as tools to be used. They are animals of low status because they are managed, and because they are cooperative in utilitarian terms. In human society, lower classes or refugees are dehumanized in the same way, even though they are capable and sentient human beings. Our view of sheep may prove more difficult to change because of social structure rather than unawareness of the empirical evidence of their intelligence and emotional capacities.

\section{References}

Amiot, C. E., \& Bastian, B. (2015). Toward a psychology of human-animal relations. Psychological Bulletin, 141, 6-47.

Fiske, S. T., Cuddy, A. J. C., Glick, P., \& Xu, J. (2002). A model of (often mixed) stereotype content: Competence and warmth respectively follow from perceived status and competition. Journal of Personality \& Social Psychology, 82, 878-902.

Franklin, R. G., Jr. (2019). Why are sheep sheepish? How perception affects animal stereotyping. Animal Sentience 25(15)

Gray, H. M., Gray, K., \& Wegner, D. M. (2007). Dimensions of mind perception. Science, 315, 619. 
Marino, L., \& Merskin, D. (2019). Intelligence, complexity, and individuality in sheep. Animal Sentience 25(1)

Sevillano, V., \& Fiske, S. T. (2016). Warmth and competence in animals. Journal of Applied Social Psychology, 46, 5, 276-293.

Sevillano, V., \& Fiske, S. T. (in press). Stereotypes, emotions, and behaviors associated with animals: a causal test of the stereotype content model and bias map. Group Processes \& Intergroup Relations [Special Issue].

Weisman, K., Dweck, C. S., \& Markman, E. M. (2017). Rethinking people's conceptions of mental life. Proceedings of the National Academy of Science, 114(43), 11374-11379. 